\title{
Apoio social e saúde: \\ pontos de vista das ciências sociais e humanas
}

\author{
Social support and health: \\ standpoints from the social and human sciences
}

Ana Maria Canesqui ${ }^{1}$

Reni Aparecida Barsaglini²

\footnotetext{
${ }^{1}$ Departamento de Medicina Preventiva e

Social, Faculdade de Ciências Médicas, Universidade Estadual de Campinas. Rua Tessália

Vieira de Camargo 126 Cidade Universitária, Barão Geraldo. 13083-887 Campinas SP. canesqui@fcm.unicamp.br ${ }^{2}$ Instituto de Saúde Coletiva, Universidade Federal de Mato Grosso.
}

\begin{abstract}
This article analyses the themes and conceptual-theoretical approaches of the social support in the literature from important international journals about social sciences and medicine, and in from 1983 to 2005 are analyzed. 259 international and 57 national abstracts was reading for the identification and computing the relations of the social support with health/disease/care. A deeper conceptual analysis about social support and the theories of social science were reported in an intentional sample of 56 international and 18 national texts. The international literature is based on the social psychology, in the several trends of the sociology and of the political science and less in the anthropology. The national literature dialogues less with the psychosocial theories and more with the sociological and anthropological theories. In this latter literature the social support approaches are concerned with social network theories; reciprocity, exchanges and cultural values. It is concluded that different trends guide the conceptualtheoretical analyses of the social support, being the international literature older, wider, more diversified and empirical, but with scarce anthropological production. The national literature is more reflexive them empirical.
\end{abstract}

Key words Social support, Theories, Social sciences, Social sciences and health
Resumo Analisam-se os temas e as abordagens teórico-conceituais do apoio social nos artigos de importantes periódicos internacionais de ciências sociais e de medicina e nacionais de Saúde Coletiva/Saúde Pública no período 1983-2005. Procedeu-se a leitura dos resumos dos 259 textos internacionais e 57 nacionais encontrados classificando e computando as relações do apoio social com a saúde/doença/cuidado. A seguir analisaram-se os conceitos e as abordagens do apoio social do ponto de vista das teorias e dos autores das ciências sociais e humanas, em uma amostra intencional de 56 textos internacionais e 18 nacionais. A literatura internacional respalda-se na psicologia social, nas várias correntes da sociologia e da ciência política e menos na antropologia. A literatura nacional dialoga menos com as teorias psicossociais e mais com as sociológicas e as antropológicas, realçando-se pela abordagem do apoio com a rede social, a solidariedade, as trocas e os valores culturais, deslocando-se da esfera individual e privada para a capacidade de organização da sociedade civil e de ações coletivas. Diferentes correntes norteiam as análises teórico-conceituais do apoio social, sendo a literatura internacional mais antiga, diversificada, empírica e escassa de produção antropológica.

Palavras-chave Apoio social, Teorias, Ciências sociais, Ciências sociais e saúde 


\section{Introdução}

Análises do apoio social e sua relação com saúde/doença/cuidado estão presentes nas pesquisas médicas, de enfermagem, psicologia, psiquiatria, epidemiologia social, sociologia e antropologia médicas, educação em saúde e saúde pública, com ampla literatura internacional e emergente nacional. Revisões bibliográficas, originárias destes campos disciplinares, concordam com a falta de consenso na definição do conceito de apoio social; o uso de diferentes teorias; preocupações com a mensuração; escassas reflexões conceituais e descompasso entre os conceitos e os instrumentos empregados nas pesquisas ${ }^{1-3}$

Instigado com as possíveis contribuições das ciências sociais e humanas ao campo da Saúde Coletiva este artigo de revisão da literatura sobre o apoio social mapeia os assuntos e suas relações com a saúde/doença/atenção, acrescentando discussão conceitual à luz de abordagens das ciências sociais identificadas nos textos selecionados.

Um breve panorama do interesse no apoio social na saúde-doença-cuidado reporta-se à segunda metade da década de 1950, com os primeiros estudos sobre a teoria do estresse e dos estressores, na demonstração dos efeitos do apoio social sobre os diferentes estressores: sociais, biológicos, ambientais, individuais (eventos de vida) e coletivos (guerras, opressão, acidentes naturais, desigualdades sociais, violência e pobreza), afetando a vulnerabilidade dos indivíduos e os quadros crônicos, psicológicos e psicossomáticos ${ }^{4}$.

$\mathrm{Na}$ década de 1970 os enfoques do apoio social deslocaram-se da psicologia para a sociologia com abordagens empíricas e realistas ${ }^{5}$, predominando os estudos quantitativos, mensuráveis e positivistas. A estas abordagens opuseramse correntes construtivistas para as quais, genericamente, a sociedade está em construção, sendo realidade objetiva, isto é exteriorizada (emancipada dos atores que a produzem) e objetivada (constituída de objetos de mundos separados dos sujeitos $)^{6}$. É neste processo de exteriorização e interiorização que se apóia o conhecimento comum tipificador, alimentando-se nas relações face a face os processos institucionalizados ${ }^{6}$.

Nesta abordagem o apoio social integra-se às ações e relações face a face dos atores entre si em determinadas situações ou contextos, com significação para eles, sem desprezar as tipificações e a institucionalização, em especial na perspectiva interacionista simbólica. A fenomenologia, por sua vez, abre espaço para que o senso comum, movido pelas tradições, crenças e conhecimentos, se expresse nas significações do apoio social nas vivências cotidianas, diferenciado do conhecimento erudito.

A abordagem cognitiva, de natureza sociopsicológica, integra o construtivismo, enfocando a percepção do apoio pelos sujeitos, segundo as características de personalidade e os modos de enfrentamento dos eventos de vida. A presença construtivista na sociologia refutou também os pressupostos da correspondência direta do apoio social com a estabilidade social, não se tratando de buscar suas funções em relação à coesão e integração do todo sistêmico, conforme pressupostos das abordagens funcionalistas.

Desde a década de 1970, as redes sociais nas quais as pessoas se inserem interessaram à Saúde Pública, relacionado-as, posteriormente ao apoio social, como resultado da integração do indivíduo em diferentes redes, ofertantes de suporte material, cognitivo, afetivo e emocional ${ }^{7}$. As redes aplicam-se aos pequenos grupos, ao sistema global e de comunicação, cujas relações estabelecidas diferenciam-se em simétricas ou assimétricas; nas suas direções e quanto à existência ou não de reciprocidade e troca. Marques ${ }^{8}$ apontou três usos de redes nas ciências sociais: como metáfora dos elos de indivíduos, entidades e idéias; os aspectos normativos de suas configurações e aplicações e os metodológicos.

$\mathrm{O}$ estudo das redes interessa à sociologia relacional, que primeiramente as descreveu a partir das relações egocentradas e sociométricas. À antropologia social britânica de Manchester originalmente interessou as estruturas das redes, nos contextos urbanos e a interferência dos tipos de conexões nos tipos de famílias; no compartilhamento ou não de responsabilidades e na oferta de apoio mútuos?.

$\mathrm{O}$ apoio social, reportado às relações sociais e às ligações entre pessoas e grupos envolve os colaboradores naturais (a família); os grupos informais (autoajuda) e os formais e institucionalizados, como as organizações de doentes, que podem compor as redes de apoio dos adoecidos, protegendo-os ou não. No espaço societário estas organizações reforçam a face política e coletiva de certas doenças, como a IDS $^{7}$, agregando demandas, participação social, a resignificação das interconexões e aprendizagem dos envolvidos.

Sob as abordagens simultâneas, macro e micro analíticas, o apoio social pode ser visto como um tipo de prestação de ajuda que repousa, de um lado nos intercâmbios, obrigações e padrões de reciprocidade entre indivíduos, grupos, famílias e instituições, portando significados para os atores neles envoltos, nas suas respectivas experiência cotidianas e contextos. De outro lado, o 
dar, receber e retribuir apoio influenciam-se e são influenciados pelas mudanças econômicas, sociais, políticas e culturais que afetam as transformações das sociedades modernas.

Algumas teorias recentes preocupam-se com as transformações estruturais destas sociedades, cujos valores individualistas e competitivos impõem maiores obstáculos à operação das relações solidárias e cooperativas, por onde pode circular o apoio social. Para Castells ${ }^{10}$ as sociedades globalizadas e informatizadas são profundamente desiguais e excludentes. Nas suas palavras "a nova sociedade surge sempre quando se observa uma transformação estrutural nas relações de produção, de poder e nas relações de experiência” (na família; nas relações de gênero, sexualidade e personalidade) "que conduzem a mudanças substanciais nas formas sociais do espaço e tempo e no aparecimento de uma nova cultura". Estas questões estruturais esgarçam e fragmentam o tecido social, dificultam a circulação do apoio social (afetivo, material, moral, informativo) nas transações entre indivíduos e grupos.

Prossegue Castells "as transformações mais fundamentais nas relações de experiência, na era da informação, é a transição a um modelo de relação social construída, primordialmente pela experiência real da relação. Atualmente as pessoas produzem formas de sociabilidade, ao invés de seguir modelos de conduta" ${ }^{10}$. Neste enfoque, admite-se que o apoio social não é uma experiência necessariamente fixa, cujos valores morais e éticos que a alimentam mostram-se flexíveis, mutáveis e em permanente construção. Assim, dispensa-se qualquer abstração e descontextualização do apoio social, na dinâmica das sociedades concretas ou sua abordagem como mero recurso ou instrumento como frequentemente aparece na literatura a ser examinada neste texto.

\section{Material e métodos}

O estudo bibliográfico deu-se em duas etapas. A primeira identificou, classificou e computou as relações do apoio com a saúde/doença/ cuidado a partir dos resumos dos 286 textos internacionais produzidos no período 1980-2005, obtidos em bases eletrônicas de periódicos (ProQuest; JSTOR; Elsevier ; SpringLinker), com a palavra chave apoio social, nos seguintes periódicos de ciências sociais e medicina: Culture Medicine and Psychiatry, Journal of Health and Social Behaviour, Medical Anthropology Quarterly; Social Science and Medicine, Qualitative Health Research; Sociology of Health and Illness. Somente o periódico Social Science and Medicine contribuiu com 70,2 \% dos textos. Excluíram-se os artigos que não abordaram as relações do apoio com a saúde/doença/cuidado ${ }^{11,12}$.

A Tabela 1 mostra a distribuição das frequências simples e relativas das relações do apoio social com a saúde/doença/cuidado na literatura internacional.

Observa-se na Tabela 1 a concentração de $55,5 \%$ dos textos nos efeitos positivos do apoio, destacando a redução do estresse e dos problemas psicológicos e sobre as enfermidades crônicas, enquanto os efeitos negativos da falta do apoio refletem-se no agravamento daqueles problemas, nos tratamentos, no uso dos serviços e na atenção à saúde.

A literatura nacional compôs-se de 51 textos, produzidos naquele período nos periódicos de Saúde Pública/Saúde Coletiva registrados na base eletrônica do sistema SciELO; nos resumos das comunicações e pôsteres publicados nos Anais do I Encontro Nacional de Ciências Sociais em Saúde, realizado em Belo Horizonte em 1993; nos Congressos de Ciências Sociais e Saúde (I, II e III), realizados no período 1991 a 2005 e nos Congressos Brasileiros de Saúde Coletiva (I, II, III, V, VI e VII) realizados no período 1986 a 2003. Textos não pertinentes ao objeto de estudo foram excluídos. A Tabela 2 sintetiza os assuntos encontrados nesta literatura.

A Tabela 2 mostra 52,7\% das referências aos efeitos positivos do apoio, dos quais a metade preocupa-se com a redução do estresse e a outra com a solidariedade, o empowerment e a cidadania, politizando o apoio social. Os efeitos da falta do apoio social quase não são discutidos, enquanto 9,8\% da literatura referem-se à religião e à cultura nas variações do apoio. Tanto na literatura internacional quanto na nacional uma parcela expressiva dos textos volta-se para os assuntos teórico-metodológicos, com escassas referências conceituais, abordando-se a grande maioria dos textos as medidas do apoio social e a validação dos instrumentos.

Na segunda etapa da pesquisa selecionaramse intencionalmente 27 textos internacionais e 18 nacionais, segundo os assuntos identificados anteriormente, cuja leitura prévia identificou a presença de autores e teorias das ciências sociais e humanas, subsidiando conceitos e abordagens do apoio social que serão comentadas ao longo deste texto.

As teorias identificadas na literatura internacional foram: as psicossociais, centradas no estresse e seus derivantes; as sistêmicas de natureza funcionalista enfatizando a integração e a coesão 
Tabela 1. Distribuição das publicações internacionais identificadas sobre apoio social segundo temas abordados, produzidas no período 1980-2005

\begin{tabular}{|c|c|c|}
\hline Temas e subtemas & $\mathbf{N}$ & $\%$ \\
\hline \multicolumn{3}{|l|}{ 1. Efeitos positivos do apoio } \\
\hline $\begin{array}{l}\text { - na redução do estresse e dos problemas mentais e psicológicos; na autoestima } \\
\text { e no bem estar psicológico }\end{array}$ & 52 & 18,0 \\
\hline $\begin{array}{l}\text { - nos ajustamentos às doenças crônicas e às perdas; na adesão aos tratamentos } \\
\text { e no uso dos serviços de saúde }\end{array}$ & 38 & 13,3 \\
\hline $\begin{array}{l}\text { - na promoção e proteção da saúde; na qualidade de vida; na prevenção } \\
\text { das doenças e no bem-estar }\end{array}$ & 45 & 15,7 \\
\hline $\begin{array}{l}\text { - na integração social e no empowerment; na quebra do isolamento social } \\
\text { e no aumento do senso de controle }\end{array}$ & 19 & 6,5 \\
\hline - na redução da morbimortalidade & 6 & 2,0 \\
\hline \multicolumn{3}{|l|}{ 2. Efeitos negativos da falta de apoio } \\
\hline $\begin{array}{l}\text { - aumento do estresse e dos problemas psicológicos; na deterioração da saúde } \\
\text { e na predisposição às doenças; no estigma; nos fatores e no comportamentos } \\
\text { de risco; no uso dos serviços e na adesão ou não aos tratamentos }\end{array}$ & 37 & 13,0 \\
\hline \multicolumn{3}{|l|}{ 3. Variações do apoio } \\
\hline - segundo gênero, etnia, situação marital; grupos de risco & 18 & 6,5 \\
\hline - cultura, religião; parentesco e família & 7 & 2,5 \\
\hline 4. Teoria e metodologia sobre apoio social & 64 & 22,5 \\
\hline Total & 286 & 100,0 \\
\hline
\end{tabular}

Tabela 2. Distribuição das publicações nacionais identificadas sobre apoio social segundo temas e subtemas abordados, produzidas no período 1983-2005

\begin{tabular}{lrr}
\hline \multicolumn{1}{c}{ Temas e subtemas } & N & $\%$ \\
\hline 1. Efeitos positivos do apoio & 13 & 25,5 \\
- na redução do estresse; na promoção da autoestima e das habilidades & 12 & 23,5 \\
- na solidariedade, no empowerment, na cidadania; nas redes e nas trocas sociais & 7 & 13,7 \\
- na promoção da saúde e na prevenção dos riscos; na adesão aos tratamentos & \\
e no uso e acesso aos serviços de saúde & 1 & 2,0 \\
2. Efeitos negativos da falta de apoio & 5 & 9,8 \\
- na deterioração da saúde; nas desigualdades sociais e na pobreza & 13 & 25,5 \\
3. Variações do apoio & $\mathbf{5 1}$ & $\mathbf{1 0 0 , 0}$ \\
- com a cultura, a religião e a família & \\
4. Teoria e metodologia sobre apoio social & \\
Total & \\
\hline
\end{tabular}

social; diferentes construtivismos centrados na percepção do apoio social segundo a psicologia cognitiva; na presença dos significados, atores e situações interativas nas abordagens mais sociológicas e no conhecimento do senso comum; comportamentos e apoio social; capital social e as ordens institucionais e culturais; o estruturalconstrutivismo e a escolha racional.

Bastante restrita a literatura nacional em relação à internacional, há interlocuções entre ambas, predominando na primeira as reflexões teóricas sobre as pesquisas empíricas sob as abordagens: 1 . redes e apoio sociais; 2 . reciprocidade, trocas e valores culturais.

\section{A teoria do estresse e a redução dos estressores}

A associação do apoio social com o estresse e os fatores psicossociais na etiologia das doenças, abordadas por Cassel $^{13}$ e Cobb $^{14}$ derivam da psicologia social norte-americana com forte influência na sociologia médica e epidemiologia social. Postulou-se que as relações sociais contribuem ao bem estar do indivíduo; moderam os efeitos do estresse psicossocial; servem de amortecedores, reduzem a vulnerabilidade dos indivíduos aos agentes estressores. Estudos com animais na década de 1930, feitos pelo médico Hans 
Selye ${ }^{15}$, desafiaram Cassel ${ }^{13}$ a indagar sobre os agentes e as relações do estresse como os processos biológicos, ambientais e sociais. Na teoria do estresse, segundo Almeida Filho ${ }^{16}$, "os processos de origem social atuam como estressores não específicos, aumentando a suscetibilidade de certos organismos diante de um estímulo nocivo direto (o agente), mediante alterações do sistema neuroendócrino (...) além de incluir a determinação constitucional da morbidade desencadeada por fatores biológicos e ambientais".

Os estressores diretos, postos por Cassel ${ }^{13}$, "podem diretamente determinar quadros psicopatológicos (ansiedade, depressão, somatizações), comportamentos de risco e, no plano biológico, imunodepressão"; enquanto os indiretos atuam "sob mediação de diferentes graus de vulnerabilidade e os estressores podem indiretamente determinar: quadros psicossomáticos e doenças crônicas não transmissíveis (hipertensão arterial, acidentes vasculares e infarto do miocárdio, diabetes, outras doenças infecto-contagiosas e neoplasias)" ${ }^{\prime 16}$.

Weinberger et al. ${ }^{17}$ entenderam que na exposição dos indivíduos aos agentes estressores o forte sistema de suporte social (sinônimo de apoio social) reduz os efeitos negativos sobre a saúde, desconsiderando os efeitos na ausência daqueles agentes. Outros estudos apontam os benefícios do apoio à saúde, independentemente da exposição dos indivíduos ao estresse.

Trata-se do modelo aditivo, na designação de Weinberger et al. ${ }^{17}$. Falta consenso sobre a influência do apoio social na saúde, na sua definição operacional e no emprego das medidas objetivas. Usam-se muito pouco nestes estudos os métodos e as técnicas qualitativas.

Nos modelos dos estressores e no aditivo, o apoio social advém das relações interpessoais, desprovido de conteúdos; qualidades e contextualização, mas com supostos efeitos, cujas ligações causais não são comprovadas pelas falhas metodológicas, dificuldades de controle das medidas e limitações dos desenhos das pesquisas ${ }^{18}$.

$\mathrm{O}$ conceito de apoio social, como defesa individual, descarta as moldagens culturais, a interferência da organização social, dos valores, normas e regulações sociais. Para Cobb $^{14}$ o apoio social remete à informação, à crença de ser amado e estimado conforme a percepção cognitiva dos indivíduos, detendo caráter protetor para eles. Integra-se à rede de compromissos mútuos dos indivíduos entre si e com os grupos, sem incluir-se nos padrões normativos e morais, que presidem as relações sociais; as trocas recíprocas e as obrigações sociais, mutáveis no tempo e espaço nas sociedades concretas.

\section{Apoio e estratégias de "coping"}

Um dos desdobramentos da teoria do estresse está em Antonowisk ${ }^{19}$ expressando o apoio a capacidade de "coping", como qualidade da personalidade, capaz de responder e manejar os recursos disponíveis no ambiente social para satisfação, bem-estar e regulação dos efeitos negativos dos agentes estressores. O "coping" é qualquer resposta às tensões externas da vida para evitar ou controlar o sofrimento emocional ${ }^{19}$. É defesa individual que usa recursos sociais (redes interpessoais), psicológicos (características de personalidade), comportamentos, cognições e a percepção das pessoas para conviver ou tolerar a enfermidade.

A literatura gerontológica e sociológica sobre as doenças crônicas, norte-americanas, abordam as estratégias e o comportamento de "coping" entre idosos para enfrentar e ajustar-se ao estresse $^{20}$, às condições crônicas ${ }^{21}$, sobreviver ao câncer de mama ${ }^{22}$; manter a qualidade de vida ${ }^{23}$, buscar atenção médica; prestar ajudas financeiras e afetivas aos idosos, cujos contatos sociais são menos frequentes nas condições de viuvez; ausência de filhos ou quando residem sozinhos.

Para Bury ${ }^{24}$, sociólogo médico inglês, o ajustamento à enfermidade crônica ultrapassa o comportamento de "coping". Assenta-se nos significados da condição crônica para os indivíduos e na sua autoimagem, moldados pela cultura e sua diversidade. Parcela da literatura inglesa socioantropológica calca-se na mútua influência entre a condição de ajuste às enfermidades de longa duração, a capacidade de mobilizar recursos de apoio, sua distribuição desigual nos grupos sociais, interferência das políticas assistenciais e da cultura na experiência dos adoecidos com a condição crônica.

Na idéia de "active coping" não aparece o apoio como recurso de personalidade. Ele se liga às especificidades culturais e relacionais de minorias étnicas, ao manejo dos colaboradores naturais, como a família e os grupos de vizinhança ${ }^{25}$. O "active coping" é iniciativa benéfica para estes grupos no acesso aos serviços de saúde, nas situações de doença e enfrentamento da lógica da organização privatista dominante do sistema de saúde norte-americano, da forte marginalização social e do preconceito social sofrido pelas minorias étnicas.

\section{Relações sociais e comportamentos nos tratamentos, prevenção; manutenção e promoção da saúde}

A antropologia médica norte-americana, tradicionalmente, abordou os efeitos das intervenções médicas nas relações sociais dos grupos servidos 
pelos programas de saúde pública, na aceitação ou recusa das intervenções tecnológicas devidas aos conflitos de autoridade e poder; as dissonâncias entre os saberes populares e científicos; as imposições dos profissionais de saúde e seu desprezo pelas crenças e agentes tradicionais de cura ${ }^{26-28}$.

Diferentes efeitos, respostas e conflitos destas intervenções nas comunidades, nas relações de parentesco, família e outros grupos sociais influenciam as decisões médicas. Os laços de solidariedade entre parentes e filhos e seus reflexos no uso de serviços de Saúde Pública foram estudados por Kunstadter ${ }^{29}$, junto com o papel da família nuclear na validação e no reconhecimento da enfermidade entre grupos mexicanos-americanos ${ }^{30} \mathrm{e}$ as relações sociais dos médicos com as populações servidas ${ }^{31}$.

Conta-se ainda com a ausência do apoio entre parentes e vizinhos, impondo limites aos programas de intervenção. $\mathrm{O}$ apoio pode ser recusado e reduzido a mero recurso supostamente disponível, mobilizável e descontextualizado das mudanças estruturais e da dinâmica das sociedades modernas onde se transformam os mecanismos de sociabilidade e cooperação, ancorados na cultura e valores; nos elos entre as pessoas, passíveis de maior individualismo, afetando a disponibilidade do apoio.

Postulam-se os efeitos positivos do apoio e das redes sociais nos comportamentos ${ }^{31}$, ajustamento e gerenciamento das doenças crônicas; nas relações dos adoecidos com os serviços e profissionais de saúde; na adesão aos tratamentos, melhora da qualidade de vida, adoção de novos estilos de vida e prevenção dos riscos às doenças, entre idosos, adoecidos crônicos; grupos minoritários ${ }^{32-34}$.

A ausência de parentes (cônjuges e filhos) de idosos associou-se à doença e à mortalidade ${ }^{35}$ contribuindo o apoio social à promoção e à manutenção da saúde física e mental, desconsiderando os estudos a disponibilidade e o uso de outros tipos de apoios, substitutos da família. A centralidade da presença da família pelos poderes públicos, nas duas últimas décadas, está na administração das doenças; na humanização do cuidado e na assistência domiciliar ${ }^{7}$. Entretanto, a família não é entidade abstrata e universal. Ela comporta múltiplos arranjos, sendo as compostas apenas pelas mulheres sozinhas e seus filhos, bastante vulneráveis socialmente.

Omitem os estudos os conflitos nas relações dos profissionais de saúde com as famílias, resultantes em rupturas, em não aprendizagem e na ausência de colaboração. Entre mexicanoamericanos o baixo acesso aos serviços de prénatal, o apoio da família e os aconselhamentos obtidos de parentes influenciam fortemente e positivamente os comportamentos de mulheres (mães) nas práticas dos cuidados pré-natais e aos recém-nascidos ${ }^{36}$.

Aqui, o apoio integra-se à prestação de um conjunto de serviços diretos e indiretos, remunerados ou não; institucionalizados ou não, incluindo diversas fontes, integrantes ou complementares aos serviços de saúde. Não se ignoram preocupações no seu uso, pelos serviços de saúde privados e mercantilizados, com a redução de custos da assistência médica e do seguro saúde nele embutidos ${ }^{37}$.

\section{Apoio social e integração social}

Ideias de que a condição de maior isolamento social ou de menor integração social afetam a saúde mental e física ou que indivíduos solteiros e isolados possuem maiores índices de tuberculose, acidentes e desordens psicológicas do que os casados estão presentes nas literaturas sociológica e epidemiológica, sem esclarecer os elos causais destas associações ${ }^{18}$.

A literatura internacional de psicologia e sociologia médica sobre o apoio e a saúde entre idosos, revista por Ramos ${ }^{38}$, reporta-se à influência durkeimiana ${ }^{3}$ nos estudos que atribuem ao apoio funções de integração e coesão social à medida que rompem o isolamento social. Durkheim não se preocupou com as relações pessoais, mas com as relações dos indivíduos com a sociedade, prevalecendo a força desta última sobre os primeiros. Reportou os contatos e os vínculos sociais a dois fatores: integração social-ligação com os outros dentro da sociedade e regulação socialligação com os outros e com as normas sociais.

$\operatorname{Ramos}^{38}$ reforça as falhas metodológicas dos estudos na comprovação das associações causais das relações sociais com as condições de saúde, onde se insere o apoio como recurso. Há estudos ultrapassando os efeitos do apoio disponível ou a sua falta sobre a frequência das relações sociais e o balanceamento da capacidade dos idosos de estabelecer trocas, rompendo com a visão de sua passividade como receptor.

A frequência e a intensidade dos contatos sociais expressam o maior grau de integração social e o sentimento de pertencimento, beneficiando o bem estar social, a saúde e a proteção contra os comportamentos desviantes, ou seja, os que fogem às normas sociais aceitas. A integração social reporta-se ainda à importância das redes sociais para os idosos ${ }^{39}$.

Estudos associam o apoio social ao tamanho das redes sociais, à integração social, ao desem- 
penho de papéis sociais e às demandas de cuidados aos doentes. Nas redes sociais constrangidas e restritas, as pessoas possuem menores chances de receber apoios, na condição de pobreza e de isolamento social.

Redes sociais são teias de relações e trocas de obrigações postas pela organização social e cultura e não somente elos entre indivíduos favorecidos somente pelos vínculos e ligações afetivas entre eles. Não são recursos abstratos mobilizados como apoio ou ajuda no cuidado e na proteção à saúde, embora sejam acionados e ofertados, circunstancialmente. O reforço das redes sociais diante da vulnerabilidade social remete a outras abordagens posteriormente consideradas.

\section{Construtivismos e apoio social}

O apoio percebido foi objeto de estudo etnográfico das concepções êmicas dos informantes que tomaram o apoio como: protetor, apatético, antagonístico e desconectado, diferenciado das classificações éticas dos pesquisadores. Levar em consideração os significados e concepções do apoio, as trocas e valores envolvidos no apoio social são implicações metodológicas importantes aos estudos da centralidade do papel da família e de outras fontes. Entre portadores de HIV/AIDS é comum não contarem com o apoio da família e sim de outras fontes institucionais devido ao estigma e isolamento social que os acompanham ${ }^{40}$.

Wethington e Kesller"1 postulam que "receber apoio" de pessoas, grupos e instituições favorece a promoção à saúde, impactando positivamente na saúde da população, enquanto "perceber o apoio" do ponto de vista cognitivo é perceber-se amado, cuidado e estimado pelos demais, podendo promover a saúde.

$\mathrm{O}$ apoio tende a ser analisado como instrumento e não como componente das relações face a face que envolve os sujeitos, nas situações cotidianas, na intersubjetividade e nos significados simbólicos que as permeiam. Embora a contribuição etnográfica de Jacobson ${ }^{42}$ indicasse os contextos situacionais, temporais e a personalidade no apoio, o papel da cultura foi omitido na sua oferta. É a cultura que fornece a matriz de significados e as regras das trocas e retribuições entre indivíduos e grupos sociais.

Para o autor o significado dos eventos de vida e a percepção e "timing" do apoio mudam entre indivíduos, em um mesmo indivíduo e nas diferentes situações e tempos. Os eventos de vida (perdas, envelhecimento, mortes e passagens) ${ }^{42}$, e as práticas de manutenção e recuperação da saúde não são manifestações exclusivas das sub- jetividades, mas são objetiváveis, regulando-se pelas normas culturais remetidas ao corpo; aos cuidados e aos consumos médicos presidindo os comportamentos individuais e grupais.

\section{As diferentes abordagens do apoio como capital social}

Capital social é um conceito frequentemente usado, desde a década de 1990, na Sociologia e na Antropologia Médicas, na Epidemiologia, na Educação, na Economia, nas Ciências Políticas, na Sociologia, nas Ciências da Informação, na Saúde Pública e nos relatórios das agências internacionais de desenvolvimento social e promoção da saúde.

O conceito formulou-se em 1916, por Lyda Hanifan, como um conjunto de elementos influentes na vida das pessoas: a boa vontade, a camaradagem, a simpatia, as interações sociais entre indivíduos e família, os integrantes das redes sociais e do valor econômico. Sociólogos e cientistas políticos teorizaram o conceito ${ }^{43}$. Dentre eles Puttman ${ }^{44}$, autor bastante citado nos estudos examinados, cujos estudos sobre os grupos no Norte e Sul da Itália incluíram o capital social na organização social, ao lado das redes, normas e confiança, nos compromissos recíprocos e nas associações de crédito rotativo.

São aspectos, presentes em várias sociedades, facilitadores da coordenação e cooperação mútuas imbricadas no "desempenho institucional" e na dimensão política, sobrepostos aos aspectos econômicos, benéficos aos indivíduos e às coletividades, desconsiderando-se sua exposição às contradições sociais e às estruturas de poder.

A produção de capital social implica o cumprimento das obrigações e a reciprocidade, contrapostos aos receios da deserção. Para Putt$\operatorname{man}^{44}$, o compromisso cívico, a democracia, a comunicação entre indivíduos e atores sociais, as interações sociais e seus elos com os dilemas da ação coletiva são componentes das ordens social, institucional e da cultura.

$\mathrm{Na}$ teoria da escolha racional, assentada no individualismo metodológico, aplicado aos campos sociológico e econômico, está Coleman ${ }^{45}$, definindo a função do capital social como facilitador das ações dos indivíduos, composto pelos sistemas de apoio familiar, pelas organizações verticais e pelas escolas religiosas, como capital humano.

A busca do interesse racional e pessoal pelos indivíduos (entre eles o uso do capital social) ou da racionalidade individualista falham por excluir a ordem social sob dois aspectos: a coordenação das expectativas entre os atores com as normas sociais e as formas de cooperação ${ }^{46}$. Es- 
tas fornecem motivações à ação, regulam as formas de comportamento, junto com os determinantes das atividades de reciprocidade, cooperação e distribuição, desconsideradas na racionalidade individualista.

Da tradição francesa estruturalista-construtivista Bourdieu ${ }^{47}$ é muito referido na literatura norte-americana selecionada. Os tipos de capitais (simbólico, cultural, econômico), apropriados pelas diferentes classes sociais, não são recursos abstratos, mas componentes do habitus de classe atuantes no campo (espaço de relações de força entre agentes sociais, de luta, concorrência e poder). Capital social é a "soma de recursos que os indivíduos adquirem pelo fato de possuírem redes duráveis de relacionamentos sociais mais ou menos institucionalizados de reconhecimento mútuo" ${ }^{47}$. Cada campo envolve mecanismos específicos de capitalização de recursos legítimos e próprios, sob a interferência do habitus de classe dos agentes envolvidos.

Ziersch ${ }^{48}$ usou Bourdieu na análise das implicações do capital social na saúde, mensurando-o em redes e valores facilitadores do acesso aos recursos de infraestrutura. Ele mediu o apoio social, seu uso, o controle social e as organizações de vizinhança em dois subúrbios australianos, mostrando os efeitos benéficos do capital social relacionados à saúde mental e não à saúde física.

Carpiano $^{49}$ usou o conceito de capital social, ancorando-se em Bourdieu e Puttman como recurso nas relações de vizinhança, suporte e controle sociais informais. $\mathrm{Na}$ análise comparada da participação nos grupos organizados e nas associações das populações pertencentes a dois bairros em Los Angeles estava a baixa associação destes componentes do apoio com o comportamento e a percepção da saúde.

Propôs-se que o capital social pode ser criado, ancorado na reciprocidade e solidariedade, ampliando o senso de comunidade e coesão. Críticas à abordagem circunscrita ao território foram feitas por desconsiderar o contexto social mais amplo e a teoria social. Os estudos mensuraram variáveis, abordaram "comunidades" como coesas e equivalentes, equivocadamente, ao conceito de espaço social, proposto por Bourdieu. Nas palavras de Stephens ${ }^{50}$ "eu sugeri que Bourdieu pode ajudar-nos, somente se colocarmos sua teoria no devido lugar" ${ }^{50}$.

Estudos epidemiológicos sociais, sociológicos e etnográficos norte-americanos sobre a relação entre capital social e saúde usam o senso de união, a solidariedade, a cooperação e a confiança como expressões do capital social das pequenas comunidades e dos grupos étnicos como be- néficos à saúde, à percepção destes problemas, à redução da violência, da delinquência juvenil e dos problemas emocionais ${ }^{51}$.

Capital e apoio social relacionam-se, supostamente, com as condições saúde (mortalidade, violência, expectativa de vida, saúde mental, gravidez na adolescência, comportamento sexual, acesso a serviços de saúde) no desenvolvimento local como redutores das desigualdades em saú$\mathrm{de}^{52}$. Nesta abordagem, na interdependência dos diferentes segmentos sociais e agentes no desenvolvimento local prevalecem os fatores socioculturais e políticos e não os econômicos. Tomamse os conceitos de intersetoriedade, colaboração, participação, ação coletiva, aprendizagem, empowerment e coesão comunitária equivalentes ao de desenvolvimento local, mesclado com o capital social. Desconsidera-se o desenvolvimento local como projeto ${ }^{53}$, caminho histórico ${ }^{54}$ ou pluridimensional ${ }^{55}$, apontados por Milani ${ }^{43}$.

Estudo etnográfico ${ }^{56}$ da localidade/território como contexto da vida social no tempo e espaço mostra a transformação histórica e a fragmentação social como característica das sociedades modernas $^{57}$, impedindo que o apoio social seja necessariamente protetor dos indivíduos jovens.

$\mathrm{Na}$ ausência de capital social, outros estudos apontaram a variação da sintomatologia depressiva, sendo o apoio percebido, mediado pelos processos socioeconômicos, os estressores e as estratégias de "coping”, entre indivíduos sem teto ${ }^{58}$. Nesta perspectiva a ausência de capital social favorece a presença do estresse, teoria esta comentada anteriormente.

\section{Usos do conceito de apoio social na literatura nacional}

É bastante restrita a literatura nacional em relação à internacional. Essa literatura dialoga com a internacional, nas múltiplas referências conceituais do apoio social como: elemento de integração e coesão social ${ }^{59,60}$, promotor da autoestima $^{61}$; como informação escrita ou não, material e econômica ${ }^{62}$; de proteção, promoção da saúde e participação social ${ }^{63}$; redutor do estresse e transcendente ao cuidado ${ }^{59,60}$

$\mathrm{O}$ apoio como recurso; suporte emocional e afetivo permeia as preocupações dos epidemiólogos de mensurá-lo, através de escalas, cuja validação vem sendo conduzida ${ }^{64}$. São escassas as referências da importância do apoio social no acesso e uso dos serviços de saúde; como componente do capital social e os efeitos negativos de sua ausência na deterioração das condições de saúde. 


\section{Redes e Apoio Social}

Apoio e redes sociais permeiam algumas abordagens anteriormente analisadas, especialmente quanto à sua importância à integração social e ao acúmulo de capital social. Na literatura nacional as redes estão como elos, conexões, relações de interdependência que favorecem as trocas, as obrigações recíprocas e os laços de dependência ${ }^{65}$. A literatura nacional dispõe de escassas pesquisas sobre elas, reconhecendo as reflexões da sua importância no envolvimento comunitário, estímulo à cooperação, reforço à autoestima; à identidade e à vontade de viver ${ }^{66}$; no fortalecimento da interdependência e da cooperação entre as associações e no desenvolvimento da cidadania e democracia ${ }^{67}$.

$\mathrm{O}$ apoio como mecanismo de solidariedade, participação e cidadania ancora-se no benefício mútuo, oferecido ou mobilizado pelos adoecidos para reivindicar direitos; enfrentar as doenças, na prevenção e promoção da saúde, ultrapassando o enfoque exclusivo no cuidado e na prestação da atenção médica individualizada aos adoecidos ${ }^{59,60}$.

Estudos das organizações de doentes nos hospitais ${ }^{68}$ ressaltam a importância das organizações não governamentais, do associativismo, das redes de solidariedade; da participação social e no aumento da responsabilidade sobre a própria saúde. Deslocando-se das instituições para os indivíduos apontou-se o maior isolamento, os poucos contatos e a rede social bastante restrita entre idosos paulistanos ${ }^{69}$.

A maior atomização dos indivíduos, a desintegração e a fragmentação movidas pelas mudanças da sociedade moderna ampliam o isolamento social, a pobreza e a exclusão social, aliadas à desconfiança mútua, ao baixo associativismo, nos países em desenvolvimento, minados na solidariedade horizontal ${ }^{44}$. $\mathrm{O}$ uso das redes sociais como estratégias políticas de proteção para amenizar a vulnerabilidade dos mais pobres, mostra-se como recursos de ampliação da cidadania e de reforço da interdependência social.

Assim sendo, a mobilização e o reforço às redes não favorecem somente o apoio, mas o tecido social e a construção das capacidades pessoais e sociais, através do empowerment que é processo e resultado da ação social favorável ao controle pelos indivíduos de suas próprias vidas, à interação com os demais e a construção da ação coletiva. Reafirma-se, portanto, nestas discussões o caráter público e coletivo e não apenas os aspectos das obrigações e dos elos interpessoais que unem os membros de uma rede e seus interesses ${ }^{65}$.

\section{Reciprocidade, trocas e valores culturais}

$\mathrm{Na}$ abordagem da dimensão cultural dos valores e da religiosidade está a prestação da "ajuda" social, como expressão da solidariedade e do cumprimento das obrigações sociais (de parentesco, vizinhança, amizade), permeando as relações sociais como valor para as classes populares $^{70,71}$. Estudos antropológicos sobre elas mostram na prestação de vários serviços a ajuda mútua, ancorada na reciprocidade das trocas e nos valores solidários, favorecendo a sobrevivência; o enfrentamento das situações de doenças e os comportamentos das pessoas ${ }^{59}$.

A proteção e o apoio da família na saúde e na doenç $\mathrm{a}^{72-74}$ reduzem o isolamento social, auxiliando as estratégias decisórias de escolha e avaliação dos tratamentos. A família como grupo de cooperação econômica, de convivência, de divisão de responsabilidades e obrigações entre seus membros favorece o dar e receber apoios e cuidado. Souza ${ }^{75}$ apontou a negligência dos estudos de saúde com os conflitos e as ambiguidades, presentes nas relações de parentesco e nos arranjos da família.

O afrouxamento dos laços de solidariedade, o declínio das redes sociais, do apoio familiar e o isolamento dos doentes estigmatizados, como os portadores de HIV/AIDS, fragilizados socialmente e nas suas condições de saúde conduzem à busca do apoio, ao exercício da cidadania e da promoção da saúde ${ }^{68,76}$ nas organizações voluntárias contra a AIDS.

Apoio social, solidariedade e rede ancoram-se na capacidade de organização da sociedade civil e nas ações coletivas deslocando-se da esfera individual e privada, como recursos instrumentais, para a esfera pública e coletiva. A etnografia de uma instituição de caridade kardecista que abriga portadores de $\mathrm{AIDS}^{77}$ mostrou, pertinentemente, sob os valores da caridade, assistência, voluntarismo religioso e acolhimento a atuação de mecanismos punitivos, de delação e mentiras; de controle da sexualidade e de trabalho compulsório como contradições e conflitos neste tipo de prática assistencial institucionalizada. As relações de conflitos, as tensões, os interesses divergentes devem ser contemplados nas ações coletivas.

\section{Conclusão}

Diferentes correntes analíticas subsidiam a discussão da importância do apoio social em relação à saúde/doença/cuidado, predominando na literatura internacional diálogos com a psicolo- 
gia social, (teorias do estresse, seus desdobramentos e cognitivas) com as várias correntes sociológicas (funcionalismo; estruturalismo-construtivista; construtivistas; relacionais e comportamentais) da ciência política (democracia e associativismo) e menos com a antropologia.

Predomina nesta literatura a mensuração do apoio social nas pesquisas quantitativas sociológicas médicas e da epidemiologia social norteamericanas, com menor presença dos estudos qualitativos, especialmente os etnográficos. A literatura internacional é muito mais antiga, ampla, diversificada e empírica do que a nacional, cujas discussões são emergentes.

A literatura nacional faz interlocução com a internacional; menos com a teoria do estresse e mais com as reflexões sociológicas, como as teorias relacionais, incluindo as redes sociais e em parte com a antropologia, reconhecendo-se a importância da cultura e do sistema de valores regulando as trocas, as obrigações e a prestação do apoio social na família e nas instituições religiosas. São restritas na produção acadêmica nacional as pesquisas empíricas, que tendem a mensurar o apoio, na busca de validação de instru-

\section{Colaboradores}

AM Canesqui trabalhou na concepção e análise do assunto, redação e revisão do texto; RA Barsaglini fez o levantamento da literatura, auxiliou na análise, na redação e na revisão do texto. mentos, especialmente nos textos de reflexões teóricas e metodológicas.

As discussões sobre redes sociais como recursos de apoio social, seus elos com a solidariedade e a ação social ancoram-se no fortalecimento da democracia; dos vínculos sociais e da interdependência, na contramão da fragmentação do tecido social na sociedade moderna. Se existem na religião e na família, especialmente nas nossas classes populares, manifestações do apoio como recurso protetor, afetivo, informacional e assistencial este merece estudos mais específicos, considerando os diferentes arranjos familiares e de religiões.

$\mathrm{Na}$ literatura nacional a proposta de incluir o apoio social na política de proteção social das organizações não governamentais, visa estimular as práticas solidárias nos grupos socialmente fragilizados e vulneráveis, como meio de participação social, exercício de cidadania e democracia. Esta proposta minimiza a presença de conflitos nestas práticas, que impõem às intervenções contínuas negociações entre os atores sociais neles envolvidos, assim como às investigações a análise das relações de poder e especificação das diferentes instituições.

\section{Referências}

1. Gonçalves TA, Pawlowiski J, Bandeira DR, Piccini CA. Avaliação do apoio social em estudos brasileiros: aspectos conceituais e instrumentos. Cien Saude Colet 2011; 16(3):1755-1769.

2. Pedro CS, Galvão CM, Rocha SMM, Nascimento IC. Apoio Social e redes sociais em enfermagem familiar: revendo conceitos. Rev Latino-Am. Enfermagem 2008; 16(2):324-327.

3. Levy RL. Social Support and compliance: a selective review and critique of treatment integrity and outcome measurement. Soc Sci Med. 1993; 17(8): 1329-1338.

4. Norbeck JS, Tilden VP. Life, stress, social support and emotional disequilibrium in complications of pregnancy: a prospective, multivariate study. J. Health Soc. Behaviour. 1983; 24(1):30-46.

5. Scambler G. Sociological Theory \& Medical Sociology. London/New York: Tavistock Publications; 1987.

6. Corcuff P. As novas sociologias. Construções da realidade social. Bauru: Edusc; 1995.

7. Adam P, Herzlich C. Sociologia da doença e da medicina. Bauru: Edusc; 2001.

8. Marques EC. Estado e Redes Sociais: permeabilidade e coesão nas políticas urbanas do Rio de Janeiro. São Paulo: Fapesp, Editora Revan; 2000

9. Bott E. Family and social networks. Roles, norms and external relationships in ordinary urban families. $2^{\text {nd }}$ ed. London: Tavistock Publications; 1957. 
10. Casttels M. La Era de La información. Economia, sociedad y cultura. Madrid: Alianza Editorial; 1997. (v. 3 Fin de Milenio)

11. Canesqui AM, Barsaglini RA. Comentários sobre a bibliografia de redes e apoio social. In: Anais do $11^{\circ}$ Congresso Mundial de Saúde Pública e $8^{\circ}$ Congresso Brasileiro de Saúde Coletiva; 2006 ago 21-25; Rio de Janeiro, Brasil.

12. Canesqui AM, Barsaglini RA. Redes e apoio social no campo da Saúde Coletiva: análise da bibliografia nacional. In: Anais do $11^{\circ}$ Congresso Mundial de Saúde Pública e $8^{\circ}$ Congresso Brasileiro de Saúde Coletiva; 2006 ago 21-25; Rio de Janeiro, Brasil.

13. Cassel J. Psychosocial process and stress: theoretical formulation. I J Health Ser. 1976; 4(3):471-482.

14. Cobb S. Social support as a moderator of life stress. Psychosom. Med. 1976, 38(5):300-314.

15. Selye H. The stress life. New York: McGraw-Hill; 1956.

16. Almeida Filho N. Modelos de determinação social das doenças crônicas não transmissíveis. Cien Saude Colet 2004; 9(4):865-884.

17. Weinberger M, Hiner SL, Tierney WM. Assessing Social Support in elderly adult. Soc Sci Med 1987; 25(9):1049-1055.

18. House JS, Landis KR, Umberson D. Social Relationship and Health. Soc Sci Med 1988; 241(4865):540544.

19. Antonowisk A. Health, Stress and Coping. San Francisco: Jossey-Bass; 1979.

20. Perlin LI. The structure of coping. J. Health Soc Behaviour 1978; 19(1):2-21.

21. Radley A, Green R. Illness as adjustment: a methodology and conceptual framework. Soc Sci Med 20(3):179-207.

22. Waxler-Morrison N, Hislop TG, Mears B, Kan L. Effects of social relationship on survival for women with breast cancer. A prospective study. Soc Sci Med 1991; 33(2):177-183.

23. Piquart M, Sörensen S. Influences of socioeconomic status, social network and competence on subjective well-being in later life: a meta-analysis. Psycol. Aging 2000:15(2);187-224.

24. Bury M. The Sociology of Chronic Illness: a Review of Research and Prospects. Sociology H. Illness.; 1993; 3(4):451-468.

25. James S, Kleinbaum J. Sociological stress and hypertension related to mortality rates in North Carolina. Am. J Public Health 1976; 66(4):354-358.

26. Freedman M. Health Education. How to strikes an anthropologist. Health. Educ J 1965; 14:18-24.

27. Foster G. Problems in Interculture Health Practice. New York: Social Science Research. Council; 1958. (Pamphlet 12).

28. Lewis O. Medicine and Politics in Mexican Village. In: Benjamin DP. Health Culture and Community. New York: Russel Sage Foundation; 1955.

29. Kunstadter P. Culture Change, Social Structure and the Use of Medical Care by Residents of Mescalero Apache Reservation. Proceedings of Annual Meeting of the American Anthropologycal Association. 1960 Oct 10-15; Mineapolis, USA.

30. Weaver T. Use of Hypotetical situation in a study of Spanish American Illness Referral Systems. Hum Org 1970; 29(2):140-154.
31. Kaplan RM, Hartwell SL. Differential effects of social support and social network on physiological and social outcomes in men and women with type II diabetes melittus. Health Psychol 1987; 6(5):387-398.

32. Tilltson TM, Smith MS. Lomis of control, social support and adeherence to the diabettes regimem. Diabetes. Educ 1996; 22(2):133-139.

33. Berkman LF, Syme SL. Social Network, host resistence and mortality. Nine years to foloow up of Alameda residents. Am.J Epidemiology 1979; 109(2): 186-200.

34. Gallant MP. The influence of social support on chronic illness self management: a review and directions for research. Health Educ Behaviour 2003; 30(2):170-195.

35. Shye D, Mullooly JP, Freeborn,DK, Pope,CR. Gender differences en the relationship between social network support characteristics to 5 year mortality among young-old versus old-old women in an community. Am J Epidemiology 1997; 146(6):516-523.

36. Clark L. La Familia: methodological issues in the assessment of perinatal social support for Mexicanas living in the United States. Soc Sci Med 2002; 53(10):1303-1320.

37. Price RH, Lorion RP, Cowen EL, editors. 14 ounces of prevention. Washington, DC: American Psychological Association; 1988.

38. Ramos MP. Apoio social e saúde entre idosos. Sociologias 2002; 4(7):156-175.

39. Ferraro K. Are Black older adult health pessimist? J Health Soc Behaviour 1993; 34(3):201-214.

40. Ciambrone D. Informal Network Among Women with HIV/AIDS. Present Support and Future Prospects. Qual Health Rev 2002; 12(7):876-896.

41. Wethington E, Kessler RC. Perceived support, received support and adjustment to stressful life events. J Health Soc Behaviour 1986; 27(1):78-88.

42. Jacobson D. The cultural context of social support and support networks. Med Anthr. Q. 1987; 1(1):4267.

43. Milani C. Teorias do Capital Social e Desenvolvimento Local: lições a partir da experiência de Pintadas (Bahia, Brasil). Projeto de Pesquisa. [Relatório na internet] s/d [acessado 2010 mar 2] 30p. Disponível em: http//www.adm.ufba.br/aapespqnepol

44. Puttman RD. Comunidade e Democracia: a experiência da Itália Moderna. Rio de Janeiro: Editora da Fundação Getúlio Vargas; 1993.

45. Coleman J. Foundation of Social Theory. Cambridge: Havard University Press; 1990.

46. Elster J. The Clement of Society. A study of social order. Cambridge: Cambridge University Press; 1989.

47. Bourdieu P. The forms of capital. In: Richardson JD, editor. Handbook of theory and research in sociology of education. Westpor: Greenwood Press; 1984. p. 241-258.

48. Ziersch AM. Health implications of access to social capital: finding from Australian study. Soc Sci Med 2005: 6(10):2119-2131.

49. Carpiano RM. Toward a neighborhood resourcebased theory of social capital for health: can Bourdieu and Sociology help? Soc Sci Med 2007; 62(1):165-175.

50. Stephens C. Social Capital in its place: using social theory to understand social capital and inequalities in health. Soc Sci Med 2008; 66(2):117-1184. 
51. Veenstra G, Luginash I, Wakefield S, Bich S, Eyles J, Elliot S. Who you know, where you live: social capital neighbourhood and health. Soc Sci Med 2006; 60(12):2799-2818.

52. Cattell V. Poor people, poor places and poor health: the mediating role of social networks and social capital. Soc Sci Med 2001; 52(3):1501-1516.

53. Perroux F. L'Economie au XX eme siècle. Paris: Press Universitaires de France; 1961.

54. Sachs I. L'ecodevelopment, strategies de transicion vers le XX eme sciecle. Paris: Syros; 1993.

55. Bartoli H. Repense le développmente. Enfin avec la pouvreté. Paris: United Nations Educational, Scientific and Cultural Organization (UNESCO); 1999.

56. Edmondson R. Social capital: a strategy for enhancing health? Soc Sci Med 2003; 57(3):1723-1733.

57. Fagg J, Curtis S, Stansfield SA, Catteli V, Tupuola AM, Arephim M. Area social fragmentation, social support for individual and psychosocial health in young adults: evidence from national survey in England. Soc Sci Med 2008; 66(2):242-252.

58. Irwin J, Laforry M, Ritchey F, Fitzpatrick K. Social assist and mental distress among the homeless: exploring the role of social support and others forms of social control on depression. Soc Sci Med 2008; 67(12):1935-1943.

59. Valla VV. Educação Popular, Saúde Comunitária e apoio social numa conjuntura de globalização. Cad Saude Publica 1999; 15(Supl. 2):4-7.

60. Lacerda A, Valla VV. As estratégias e táticas de rede e apoio social presentes no cotidiano da população como formas de enfrentamento dos problemas de Saúde. Livro de Resumos II Congresso Brasileiro de Saúde Coletiva 2003 Jul/Ago 29-2. Brasília (DF). Cien Saude Colet 2003; 8(Supl. 2):504.

61. Viana EC. Grupo de mulheres: uma experiência positiva. Livro de Resumos VII Congresso Brasileiro de Saúde Coletiva. 2003 Jul/Ago 29-2. Brasília (DF). Cien Saude Colet 2003; 8(Supl. 1):507.

62. Leal MC, Pietrukowicz MCL, Valla VV. Apoio social e saúde na forma de enfrentamento. Livro de Resumos. VI Congresso Brasileiro de Saúde Coletiva. 2000 Ago/Set 28-1. Salvador (BA). Cien Saude Colet 2000; 5(Supl. 8):226.

63. Dalmaso ASW. Suporte social para promoção da saúde, estratégia de atenção básica. Livro de Resumos VI Congresso de Saúde Coletiva. 2000 ago/set 28-1. Salvador (BA). Cien Saude Colet 2000; 15(Supl. 8): 226.

64. Costa AG, Ludemir AB. Transtornos mentais comuns e apoio social: estudo em comunidade rural da zona da Mata de Pernambuco. Cad Saude Publica $2005 ; 21(5): 73-79$.
65. Martins PH. As redes sociais, o sistema de dádiva e o paradoxo sociológico. In: Martins $\mathrm{PH}$, Fontes B, organizadores. Redes sociais e saúde: novas possibilidades teóricas. Recife: Editora Universitária da UFPE; 2004. p. 21-48.

66. Valla VV. Redes sociais, poder e saúde à luz das classes populares numa conjuntura de crise. Interface Comum Saúde Educ 2000; 4(7):37-56.

67. Landin L. Sem fins lucrativos: as organizações não governamentais no Brasil. Rio de Janeiro: ISER; 1988.

68. Andrade GRRN, Vaitsman J. Apoio Social e redes: conectando solidariedade. Cien Saude Colet 2002; 7(4):925-934.

69. Rosa TEC, Benício MHA, Alves MCGP, Lebrão ML Aspectos estruturais e funcionais do apoio de idosos do Município de São Paulo, Brasil. Cad Saude Publica 2007; 23(12):2982-2992.

70. Valla VV. Apoio Social e Saúde: buscando compreender as falas das classes populares. In: Livro de Resumos V Congresso Brasileiro de Saúde Coletiva. V Congresso Paulista de Saúde Pública; 1997 ago 25-29; Águas de Lindóia (SP). p. 41.

71. Pietrukowicz MCL, Valla VV. Apoio Social e Religião: uma forma de enfrentamento dos problemas de saúde. In Programa/Resumos III Congresso Brasileiro de Ciências Sociais em Saúde; 1999 dez 3-6; São Paulo (SP). p. 97.

72. Carvalho AFF, Brhuel D, Silva J, Morais P. Vida Familiar e câncer de mama: uma abordagem social. In: Anais I Encontro Nacional de Ciências Sociais e Saúde; 1993 set/out 28-1. Belo Horizonte (MG). p. 79.

73. Bastos Neto O. Família e Doença Mental. In: Anais do I Encontro Nacional de Ciências Sociais e Saúde; 1993 set/out 28- 1; Belo Horizonte (MG). p. 121.

74. Romanelli G. Família, Parentesco e Cuidados com doentes. In: Livro Resumo III Congresso de Saúde Coletiva e I Encontro de Saúde Coletiva do Cone Sul; 1992 set 16-25; Porto Alegre (RS). p. 73.

75. Souza I. Hostilidade e conflito na lida com a doença mental: a entrada em cena de aspectos negligenciados nos estudos de redes sociais. In: Anais Programa/Resumos $1^{\circ}$ Congresso Brasileiro de Ciências Sociais em Saúde; 1995 set 7-10; Curitiba (PR). p. 121.

76. Guimarães W. Rede de comunidade popular na luta contra a AIDS. Trabalhando por prevenção e solidariedade no Rio de Janeiro. In Livro de Resumos. VII Congresso Brasileiro de Saúde Coletiva; 2003 jul/ago 29-2; Brasília (DF). Cien Saude Colet 2003; 8(Supl. 1):20.

77. Pereira PPG. O Terror da Dádiva. Goiânia: Editora Vieira. Cânone Editorial; 2004. 